\title{
Introduction of a modified double-lumen tube
}

\author{
Hamaguchi Shinsuke ${ }^{1}$ (])
}

Received: 11 May 2018 / Accepted: 12 May 2018 / Published online: 22 May 2018

(c) The Author(s) 2018

Keywords Double-lumen tube $\cdot$ Bronchial cuff $\cdot$ Deflation

To the Editor:

Since 1949, the double-lumen tube (DLT) has played an important role in safe anesthetic management for intrathoracic surgeries, such as lung or esophageal surgeries requiring differential lung ventilation (DLV) [1,2]. Here, I present a modified DLT to safely perform DLV.

There was a clinical problem, where Broncho-Cath ${ }^{\mathrm{TM}}$ (Covidien, USA) could not deflate bronchial cuff (blue cuff) when the tube was bent to a certain shape. The defective bronchial cuff deflation might be attributed to the kink in intratubal bronchial cuff lumen due to the curvature of it (supplementary Fig. 1).

Therefore, the location of bronchial cuff vent intratubal lumen in the existing tube may be inadequate. I discussed this aspect with the staff of Covidien Japan and suggested changes to the position of the cuff air delivery lumen while maintaining the strength and elasticity of the tube. Specifically, the modified Broncho-Cath ${ }^{\mathrm{TM}}$ exhibited three intratubal lumens in a position that is difficult to kink, which differs from the previous two intratubal lumens type (supplementary Fig. 2). After customization by the staff of Covidien
Japan based on my opinion, the tube has been marketed as the Shiley ${ }^{\mathrm{TM}}$ Endobronchial Tube.

Acknowledgements We would like to thank Editage (http://www.edita ge.jp) for English language editing.

\section{Compliance with ethical standards}

Conflict of interest The authors declare that they have no competing interests.

Open Access This article is distributed under the terms of the Creative Commons Attribution 4.0 International License (http://creativeco mmons.org/licenses/by/4.0/), which permits unrestricted use, distribution, and reproduction in any medium, provided you give appropriate credit to the original author(s) and the source, provide a link to the Creative Commons license, and indicate if changes were made.

\section{References}

1. Robertshaw FL. Low resistance double-lumen endobronchial tubes. Br J Anaesth. 1962;34:576-9.

2. Benumof JL, Partridge BL, Salvatierra C, Keating J. Margin of safety in positioning modern double-lumen endotracheal tubes. Anesthesiology. 1987;67:729-38.
Electronic supplementary material The online version of this article (https://doi.org/10.1007/s00540-018-2511-y) contains supplementary material, which is available to authorized users.

Hamaguchi Shinsuke

s-hama@dokkyomed.ac.jp

1 Department of Anesthesiology and Pain Medicine, Dokkyo University School of Medicine, 880 Kitakobayashi, Mibu, Tochigi 321-0293, Japan 